\title{
KARAKTERISASI BLOK REM KERETA API BERBAHAN AL-SiC BERDASARKAN KOMPOSISI MATERIAL
}

\author{
Ipung Kurniawan ${ }^{1}$, A.P. Bayuseno ${ }^{2}$ \\ 1) Program Studi Teknik Mesin Politeknik Cilacap \\ 2) Program Studi Teknik Mesin Universitas Diponegoro Semarang
}

\begin{abstract}
Brake blocks is a vital component in the braking system of trains. Generally material brake blocks made of cast iron. But the usage is still less effective than the weight and resistance to wear. Al-SiC composites with the variation of weight fraction of 5, 10 and $15 \% \mathrm{SiC}$ is expected to address the problem as expected. Stir casting method was chosen for the process of formation of Metal Matrix Composites (MMC), which includes the characterization of microstructure and wear of materials. Wear and tear on the material tested by the method ogoshi at $2.12 \mathrm{~kg}$ load and a constant sliding speed $0.244 \mathrm{~m} / \mathrm{s}$ for 60 seconds. Small value indicates the specific wear resistance of materials against wear is good.
\end{abstract}

Key words: Block train brakes, MMC Al-SiC, stir casting.

\section{PENDAHULUAN}

Kanvas rem (blok rem) merupakan salah satu komponen kereta api yang paling sering diganti. Umumnya material blok rem kereta api yang digunakan adalah besi cor kelabu. Pemakaian blok rem komposit menggantikan blok rem berbahan besi cor untuk kanvas kereta api di Indonesia sudah dimulai sejak dasa warsa terakhir. Blok rem komposit pada mulanya diperkenalkan di Indonesia oleh para importir asing dengan blok rem merk Fituris (Australia), Ferodo (Inggris), Marquist (China), Nabco (Jepang) dan dari Sideria. Baru sejak tahun 2002 blok rem komposit diproduksi di tanah air, dan saat ini sudah ada sekurang-kurangnya 3 (tiga) pabrikan blok rem komposit lokal dan 2 (dua) pabrikan telah mendapat sertifikasi dari PT. KAI (Suryadi, 2011).

Blok rem yang materialnya menggunakan besi cor mempunyai berat $11-12 \mathrm{~kg}$, sehingga mempersulit proses pemasangan atau biaya pemasangan cukup besar. Umur pemakaian hanya mencapai satu bulan dan nilai jual bahan bekasnya masih relatif tinggi, sehingga rentan pencurian (Suryadi, 2011). Berbagai macam usaha dilakukan untuk mencari alternatif material yang mempunyai sifat ringan, keras dan tahan aus sebagai pengganti blok rem berbahan besi cor. Namun demikian hasil yang diperoleh belum bisa seperti yang diharapkan. Salah satu upaya yang telah ditempuh adalah menggabungkan dua material penyusunnya, yaitu matriks dan penguat. Penggabungan dua material penyusun untuk menghasilkan material baru yang lebih baik dari sebelumnya sering disebut dengan istilah komposit (Scity dkk, 2002).

Logam aluminium (Al) sebagai matriks, bila ditinjau dari sifat mekanik, seperti nilai kekerasan (hardness) sangat rendah. Oleh karena itu logam Al sebagai material monolotik memiliki banyak kelemahan, seperti: kekuatan mekanik, kekakuan, dan koefisien muainya. Kelebihan logam Al, antara lain memiliki: bobot yang ringan, tahan terhadap korosi, dan mudah dibentuk (Zhongliang, 2001).

Salah satu cara untuk meningkatkan ketahanan aus logam, maka perlu dilakukan penguatan pada logam tersebut, yaitu dengan cara ditambahkan dengan material yang keras, misalnya bahan keramik. Jenis-jenis bahan keramik yang biasa digunakan antara 
lain: $\mathrm{Al}_{2} \mathrm{O}_{3}, \mathrm{SiC}, \mathrm{TiC}$, dan $\mathrm{ZrO}_{2}$. Diantara jenis keramik tersebut yang paling keras adalah $\mathrm{SiC}$ (Jamaliah, 2003). Penggabungan antara material Al sebagai matriks dengan keramik $\mathrm{SiC}$ sebagai penguatnya tergolong dalam jenis material komposit, yaitu Komposit Matriks Logam (KML) (Scity dkk, 2002).

Komposit adalah perpaduan dari beberapa bahan yang dipilih berdasarkan kombinasi sifat fisik masing-masing material penyusunnya untuk menghasilkan material baru yang unik, dibandingkan dengan sifat material dasarnya sebelum dikombinasikan, terjadi ikatan antara masing-masing material penyusunnya (Scity, 2002). Berdasarkan bahan matriks yang digunakan, maka komposit dapat diklasifikasikan ke dalam tiga kelompok, yaitu (Scity, 2002) :

a. Komposit matriks logam (Metal Matrix Composite)

b. Komposit matriks polimer (Polimer Matrix Composite)

c. Komposit matriks keramik (Ceramics Matrix Composite)

Sedangkan berdasarkan jenis penguatnya, maka material komposit dapat dijelaskan sebagai berikut :

a. Particulate composite, penguatnya berbentuk partikel

b. Fibre composite, penguatnya berbentuk serat

c. Structural composite, penguatnya berbentuk lapisan

Proses pembentukan komposit dengan matriks $\mathrm{Al}$ pada skala industri diklasifikasikan dalam 2 (dua) kelompok utama yaitu: solid state processes (proses keadaan padat) dan liquid state processes (proses keadaan cair) (Surappa, 2003). Pada penelitian ini dipilih metode cair berupa stir casting untuk pembentukan blok rem kereta api berbahan KML Al-SiC. Stir casting adalah proses pengecoran dengan cara menambahkan suatu logam murni (biasanya $\mathrm{Al}$ ) dengan sebuah penguat, dengan cara melebur logam murni tersebut, kemudian logam murni yang sudah mencair tersebut diaduk-aduk secara terus menerus hingga berbentuk sebuah pusaran, kemudian penguat (berupa serbuk) tersebut ducampurkan sedikit demi sedikit melalui tepi dari pusaran yang telah terbentuk (Davis, 1993).

Raharjo (2010) meneliti pembuatan KML Al-SiC dengan metode stir casting untuk pembuatan komponen blok rem kereta api. Variasi paremeter dalam penelitian ini penambahan serbuk $\mathrm{SiC}$ dengan fraksi berat 2 dan $5 \%$. Hasil penelitiannya dapat ditunjukkan pada Tabel 1.

Tabel 1 Hasil penelitian KML Al-SiC 2-5\% Raharjo (2010)

\begin{tabular}{cc} 
Material & $\begin{array}{c}\text { Keausan } \\
\left(\mathrm{mm}^{2} / \mathrm{kg}\right)\end{array}$ \\
\hline $\mathrm{Al}-\mathrm{SiC} 2 \%$ & $7,527 \times 10^{-8}$ \\
$\mathrm{Al}-\mathrm{SiC} 5 \%$ & $11,156 \times 10^{-8}$ \\
Besi cor & $5,612 \times 10^{-8}$ \\
\hline
\end{tabular}

Berdasarkan tabel diatas menunjukkan bahwa nilai keausan terus bertambah dengan meningkatnya penambahan serbuk $\mathrm{SiC}$.

Singla, dkk (2009) meneliti pembuatan KML Al-SiC(320 grit) dengan metode stir casting. Variasi parameter dalam penelitian ini penambahan fraksi berat SiC 5, 10, 20 dan $25 \%$ terhadap tingkat keausan. Uji keausan menggunakan metode pin-on-disk dengan beban uji normal 5, 7,9 dan $11 \mathrm{~N}$ pada kecepatan geser konstan 1,0 m/s pada jarak geser total 1,8 km . Material untuk disk berupa baja EN 32 dengan tingkat kekerasan 65 HRC. Hasil pengujian menunjukkan bahwa dengan bertambahnya fraksi berat, volume yang hilang semakin menurun, dan koefisien gesek rata-rata semakin meningkat. Nilai terbaik diperoleh pada fraksi berat $20 \%$. 
Basavarajappa, dkk (2006) meneliti pembuatan KML Al(2219)-SiC(25 $\mu \mathrm{m})$ dengan metode stir casting. Variasi parameter dalam penelitian ini penambahan fraksi berat $\mathrm{SiC} 5,10$ dan $15 \%$ terhadap tingkat keausan. Uji keausan menggunakan metode pin-on-disk dengan beban uji normal 0-60 N dan kecepatan geser 1,53 m/s, $3 \mathrm{~m} / \mathrm{s}, 4,6 \mathrm{~m} / \mathrm{s}$ dan $6,1 \mathrm{~m} / \mathrm{s}$ pada jarak konstan $5000 \mathrm{~m}$. Material untuk disk berupa baja EN 32 dengan tingkat kekerasan 65 HRC. Pengadukan dilakukan selama 5 menit dengan kecepatan 300$350 \mathrm{rpm}$. Material pengaduk berupa stainless steel yang dilapisi aluminite dengan tujuan untuk melindungi material pengaduk agar tidak terkorosi. Pengecoran dilakukan dengan cetakan permanen yang berukuran diameter $10 \mathrm{~mm}$ dan tingginya $50 \mathrm{~mm}$. Hasil penelitian menunjukkan bahwa dengan bertambahnya fraksi berat, volume yang hilang dan laju aus semakin menurun. Nilai terbaik diperoleh pada fraksi berat $15 \%$.

Ramachandra, dkk (2003) meneliti pembuatan KML Al(LM6)-SiC $(20 \mu \mathrm{m})$ dengan metode stir casting secara manual. Variasi parameter dalam penelitian ini penambahan fraksi berat $\mathrm{SiC} 5,10$ dan 12\% terhadap keausan material. Partikel SiC sebelumnya dipanaskan terlebih dahulu pada temperatur $300{ }^{\circ} \mathrm{C}$. Pengadukan dilakukan pada temperatur $720{ }^{\circ} \mathrm{C}$ selama 5-10 menit (500 rpm). Selama pengadukan ditambahkan sedikit magnesium dengan tujuan untuk meningkatkan wettability partikel SiC. Cetakan terbuat dari besi cor dengan ukuran diameter $80 \mathrm{~mm}$ dan tinggi $150 \mathrm{~mm}$, kemudian penuangan dilakukan pada temperatur $680{ }^{\circ} \mathrm{C}$. Hasil penelitian menunjukkan bahwa dengan meningkatnya fraksi berat dapat meningkatkan nilai ketahanan terhadap aus.

Penelitian ini dilakukan untuk menyempurnakan penelitian yang sudah pernah dilakukan sebelumnya, yaitu dengan memodifikasi fraksi penguat. Modifikasi fraksi penguat KML Al-SiC yang digunakan 5, 10 dan 15\% dengan stir casting untuk proses pembentukannya. Parameter yang diteliti meliputi struktur mikro dan tingkat keausan material. Luaran yang diharapkan dari penelitian ini adalah hasil analisis tentang karakteristik material blok rem kereta api. Penguasaan tentang teknologi pembuatan material komposit $\mathrm{Al}-\mathrm{SiC}$ dapat mengatasi ketergantungan produk import, terutama komponen kereta api seperti blok rem.

\section{METODE PENELITIAN}

2.1. Persiapan Material

Penelitian ini material untuk matriks yang digunakan adalah Al limbah dengan komposisi di Tabel 2 sebagai berikut:

Tabel 2 Komposisi ingot limbah Al

\begin{tabular}{cc} 
Komposisi Kimia & $(\% \mathrm{wt})$ \\
$\mathrm{Al}$ & 98,07 \\
$\mathrm{Fe}$ & 0,491 \\
$\mathrm{Si}$ & 0,478 \\
$\mathrm{Mg}$ & 0,411 \\
$\mathrm{Cu}$ & 0,121 \\
$\mathrm{Zn}$ & 0,115 \\
$\mathrm{~Pb}$ & 0,0734 \\
$\mathrm{Ca}$ & $* 0,0558$ \\
$\mathrm{Ni}$ & 0,0206 \\
$\mathrm{Zr}$ & 0,0173 \\
$\mathrm{Ti}$ & 0,0170 \\
$\mathrm{Cr}$ & 0,0166 \\
$\mathrm{Sn}$ & $<0,0500$ \\
$\mathrm{~V}$ & $<0,0100$ \\
\hline
\end{tabular}




\begin{tabular}{cc}
\hline $\mathrm{Sr}$ & $<0,0005$ \\
$\mathrm{Be}$ & $<0,0001$ \\
\hline
\end{tabular}

Serbuk SiC sebagai penguat yang digunakan dengan ukuran butir 45-75 $\mu \mathrm{m}$. Sebelum peleburan timbang ingot $\mathrm{Al}$ dan serbuk $\mathrm{SiC}$ sesuai variasi komposisi yang sudah ditentukan. Peleburan Al dilakukan pada temperatur $700{ }^{\circ} \mathrm{C}$, kemudian dimasukkan serbuk $\mathrm{SiC}$ diteruskan dengan pengadukan selama 10 menit $(610 \mathrm{rpm})$. Sebelum proses penuangan, cetakan dipanaskan terlebih dahulu pada temperatur $200{ }^{\circ} \mathrm{C}$. Material untuk pengaduk yang digunakan adalah stainless steel agar terhindar dari korosi disaat pengadukan berlangsung. Tungku peleburan yang digunakan dapat dilihat pada Gambar 1 berbahan baku LPG dilengkapi dengan blower. Dimensi ukuran hasil coran panjang 110 $\mathrm{mm}$ dengan diameter $23 \mathrm{~mm}$ serta sampel uji seperti terlihat pada Gambar 2.
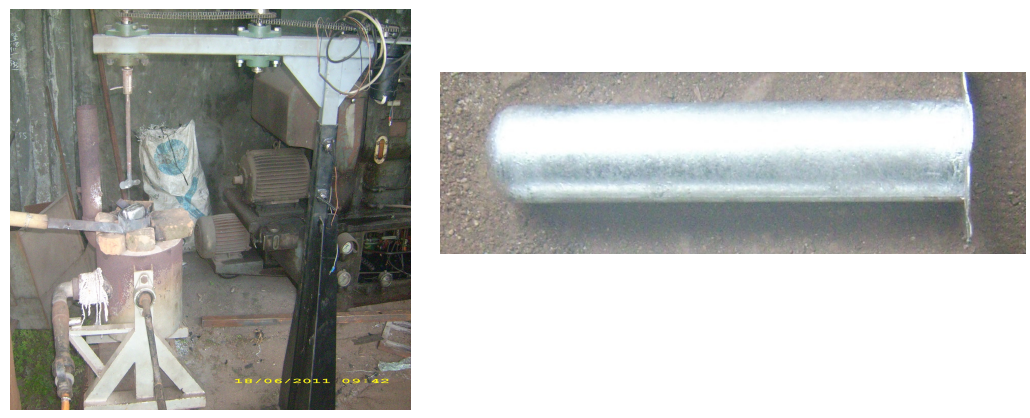

Gambar 1 Tungku peleburan

Gambar 2 Hasil coran

\subsection{Pengujian Struktur Mikro}

Pengujian struktur mikro bertujuan untuk mengetahui ukuran butir, twins yang terjadi serta distribusi partikel pada saat fase kedua. Pengujian struktur mikro memerlukan bantuan alat berupa mikroskop (ASM, 1996). Langkah-langkah untuk melakukan pengamatan struktur mikro dapat memakai referensi ASTM E3 dari persiapan sempel dan prosedur pengujian mikroskop. Pada penelitian ini menggunakan mikroskop merk Olympus BX 41M dan kamera digital merk Olympus C5060WZ. Pengambilan data dilakukan pada bagian bawah dari hasil coran.

\subsection{Pengujian Keausan}

Keausan merupakan hilangnya bahan dari suatu permukaan atau perpindahan bahan dari permukaannya ke bagian yang lain atau bergeraknya bahan pada suatu permukaan (Almen, 1950). Pengujian keausan pada penelitian ini menggunakan metode ogoshi dengan beban 2,12 kg dan kecepatan geser konstan $0,244 \mathrm{~m} / \mathrm{s}$ selama 60 detik. Pengambilan sampel uji dilakukan pada bagian bawah hasil coran, karena distribusi SiC terbanyak pada bagian bawah material. Hal ini dibuktikan dengan hasil pengujian densitas dan kekerasan material sebelumnya. Mesin dan sampel uji keausan ditunjukan pada Gambar 3 dan 4. Besarnya keausan spesifik dapat dihitung dengan menggunakan rumus sebagai berikut:

$W s=\frac{B \cdot b_{0}{ }^{3}}{8 \cdot r \cdot P_{0} \cdot l_{0}}$

Dimana:

Ws : Keausan spesifik $\left(\mathrm{mm}^{2} / \mathrm{kg}\right)$

B : Tebal piringan pengaus $(3 \mathrm{~mm})$ 
$\mathrm{b}_{0} \quad$ : Lebar keausan pada benda uji $(\mathrm{mm})$

$\mathrm{r}$ : Jari-jari piringan pengaus $(13,5 \mathrm{~mm})$

$\mathrm{P}_{0}$ : Gaya tekan/beban pada proses keausan berlangsung $(\mathrm{kg})$

$1_{0}$ : Jarak tempuh pada proses pengausan $(\mathrm{m})$
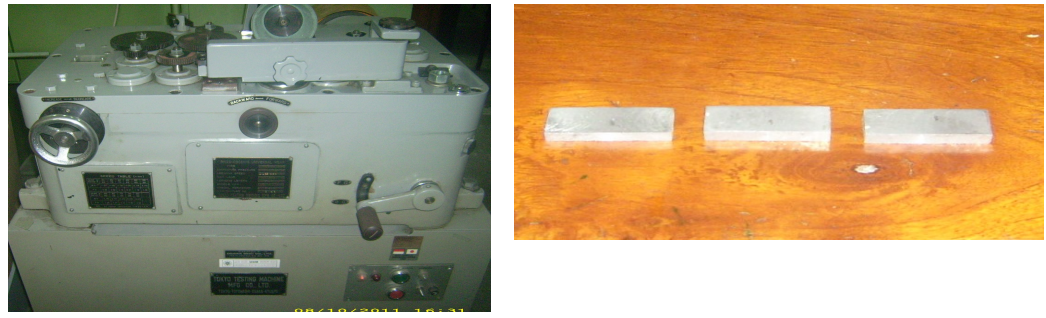

Gambar 3 Ogoshi High Speed Universal Wear Gambar 4 Spesimen uji keausan Testing Machine (Type OAT-U)

\section{HASIL DAN PEMBAHASAN}

3.1. Struktur Mikro

Pengujian struktur mikro material blok rem kereta api dilakukan dengan menggunakan etsa nital untuk besi cor sedangkan $\mathrm{Al}$ dan $\mathrm{Al}-\mathrm{SiC}$ menggunakan etsa $\mathrm{HF}$ 0,5. Hasil pengujian struktur mikro besi cor, $\mathrm{Al}$ dan $\mathrm{Al}-\mathrm{SiC}$ 5, 10, 15\% ditunjukkan pada Gambar 5. Pengambilan gambar menggunakan perbesaran 500x.

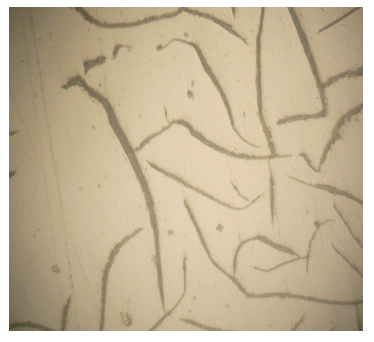

Besi cor kelabu

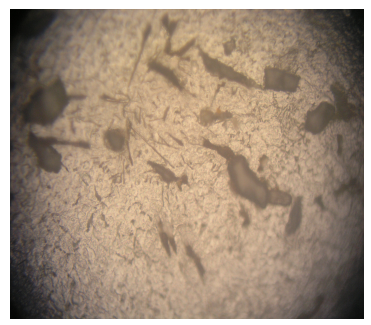

$\mathrm{Al}-\mathrm{SiC} 10 \%$

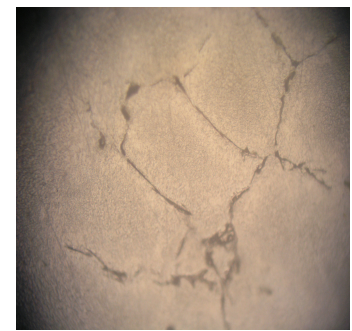

$\mathrm{Al}$

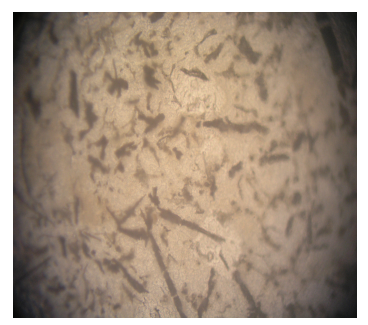

$\mathrm{Al}-\mathrm{SiC} 15 \%$

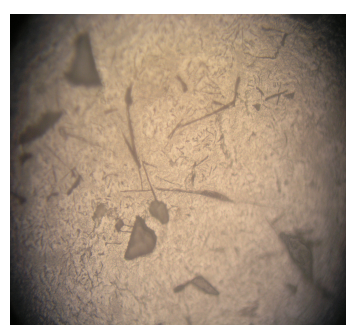

$\mathrm{Al}-\mathrm{SiC} 5 \%$

Gambar 5 Struktur mikro besi cor, Al dan Al-SiC 5, 10, 15\%

Struktur mikro yang diperoleh dari hasil pemotretan menghasilkan batas butir yang sangat jelas. Pada struktur mikro besi cor kelabu terlihat serpihan grafit (graphite flakes) yang berwarna gelap sangat jelas, dan tersebar merata. Grafit tersebut berpengaruh terhadap kekerasan material besi cor tersebut. Semakin banyak matriks grafit yang 
terbentuk maka material semakin lunak. Ferit pada hasil foto mikro besi cor terlihat jelas yang berwarna terang. Struktur mikro pada material Al mempunyai fasa $\alpha$-Al. Struktur mikro pada material Al-SiC memperlihatkan persebaran $\mathrm{SiC}$ (gelap) yang random didalam matriks $\mathrm{Al}($ terang), persebaran partikel $\mathrm{SiC}$ lebih banyak dengan bertambahnya fraksi berat. Dari gambar di atas nampak jelas sebaran $\mathrm{SiC}$ lebih merata dan distribusinya lebih banyak pada fraksi berat $15 \%$ dibandingkan fraksi berat 5 dan $10 \%$. Hal ini tentunya memberikan pengaruh yang signifikan pada peningkatan nilai densitas dan kekerasan serta menurunkan keausan spesific material.

\subsection{Keausan}

Pengujian keausan spesific pada material blok rem kereta api dilakukan tiga kali pengulangan pada masing-masing spesimen. Hasil pengujian keausan spesific material besi cor, Al dan Al-SiC 5, 10, 15\% dapat dilihat pada Gambar 6 .

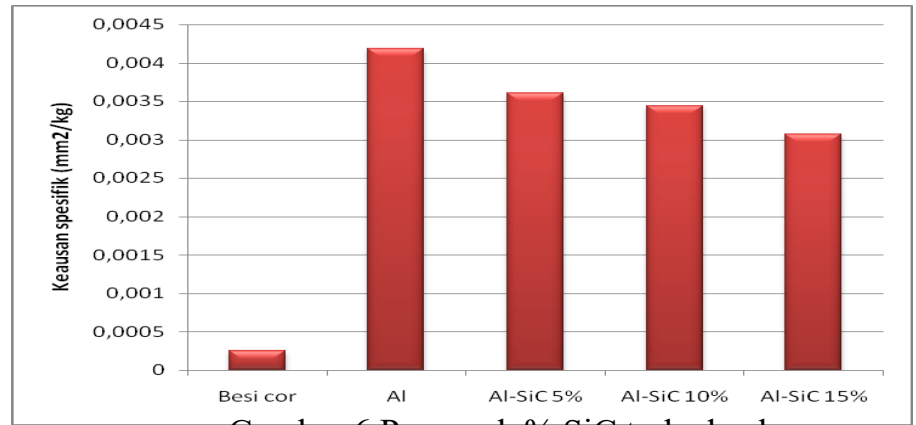

Gambar 6 Pengaruh \% SiC terhadap keausan spesifik

Keausan spesific pada gambar di atas memperlihatkan bahwa semakin bertambahnya fraksi berat $\mathrm{SiC}$ maka keausan spesifik dari material komposit akan semakin menurun. Fraksi berat yang semakin banyak akan menyebabkan peningkatan sebaran SiC. Dengan semakin banyaknya sebaran $\mathrm{SiC}$ maka densitas dan kekerasan dari material komposit yang terbentuk semakin tinggi dan keausan spesifik rendah. Semakin rendah nilai keausan spesifik maka material tersebut akan semakin tahan terhadap abrasi atau keausan. Dari percobaan di atas diketahui bahwa keausan spesifik tertinggi didapat pada Al yaitu $0,004186 \mathrm{~mm}^{2} / \mathrm{kg}$ dan keausan spesifik terendah didapat pada besi cor yaitu $0,000248 \mathrm{~mm}^{2} / \mathrm{kg}$. Nilai ini mempunyai trend yang sama dengan hasil penelitian Singla, dkk (2009), Basavarajappa, dkk (2006) dan Ramachandra, dkk (2003) tentang pengujian keausan KML Al-SiC.

\section{KESIMPULAN}

Bertambahnya fraksi penguat akan memperbanyak sebaran $\mathrm{SiC}$ yang terbentuk dan distribusinya lebih homogen. Keausan spesifik material semakin menurun dengan bertambahnya fraksi penguat, artinya material lebih tahan terhadap abrasi atau keausan.

\section{DAFTAR PUSTAKA}

Almen, J.O. (1950). In Mechanical Wear (ed J.T. Burwell), Amarican Society for Metals, pp. 229-288.

ASM Handbooks Comitte, (1996), ASM Specially Handbooks Cast Iron, ASM International 
Davis, JR., et al. (1993) “Speciallty Handbook, Alumunium and Alumunium Alloys", ASM International Handbook Comitee, Ohio.

htp://suryadi05.multiply.com/journal/item/3 (Diakses, 15 Maret 2011).

Intruction Manual, "Ogoshi High Speed Universal Wear Testing Machine Type OAT-U"

Jamaliah Idris, 2003, Kajian Sifat Keausan dan Kekerasan Komposit Matriks Aluminium, Universiti Teknologi Malaysia, Malaysia.

M K Surappa, 2003, Aluminium Matrix Composites: Challenges and Opportunities.

Raharjo E. Nugroho, 2010, Karakterisasi Sifat Mekanik Komposit Matriks Logam Al/SiC Pada Bahan Rem Kereta Api, Universitas Diponegoro, Semarang.

Ramachandra M. and Radhakrishna K., 2003, Processing - Mechanical and Wear Properties of Aluminium Based Metal Matrix Composite Synthesized Using Vortex Method.

S. Basavarajappa, dkk, 2006, Dry Sliding Wear Behavior of Al 2219/SiC Metal Matrix Composites, Materials Science-Poland, Vol. 24.

Sciti, D., and Bellosi, A., 2002, Microstructure and Properties of Alumina-SiC nanocomposites Prepared from Ultrafine Powder, Journal of Material Science 37, Kluwer Academic Publishers.

Singla Manoj, dkk, 2009, Study of Wear Properties of Al-SiC Composites, Journal of Minerals \& Materials Characterization \& Engineering, Vol. 8, No.10, pp.813-819.

"Standard Guide for Preparation of Metallographic Specimens" ASTM Designation E301

Zhongliang Shi, 2001, The Oxidation of SiC Particle and Its Interfacial Characteristics in Al-Matrix Composites, Journal of Material Science 36, pp. 2441-2449, Kluwer Academic Publiser. 